Published in final edited form as:

J Neurooncol. 2011 September ; 104(2): 535-542. doi:10.1007/s11060-010-0506-0.

\title{
Cancer susceptibility variants and the risk of adult glioma in a US case-control study
}

\author{
Kathleen M. Egan, \\ Department of Cancer Epidemiology \& Genetics, H. Lee Moffitt Cancer Center \& Research \\ Institute, Tampa, FL 33612, USA
}

Reid C. Thompson,

Department of Neurological Surgery, Vanderbilt University Medical Center, Nashville, TN 37232 , USA

\section{B. Nabors,}

Neuro-oncology Program, University of Alabama at Birmingham, Birmingham, AL 35294, USA

Jeffrey J. Olson,

Department of Neurosurgery, Emory School of Medicine, Atlanta, GA 30322, USA

Daniel J. Brat,

Department of Pathology and Laboratory Medicine, Emory School of Medicine, Atlanta, GA 30322, USA

\section{Renato V. LaRocca,}

Kentuckiana Cancer Institute, Louisville, KY 40202, USA

\section{Steven Brem,}

Department of Neurosurgery, H. Lee Moffitt Cancer Center \& Research Institute, Tampa, FL 33612, USA

\section{Paul L. Moots,}

Department of Neurology, Vanderbilt University Medical Center, Nashville, TN 37232, USA

\section{Melissa H. Madden,}

Department of Cancer Epidemiology \& Genetics, H. Lee Moffitt Cancer Center \& Research Institute, Tampa, FL 33612, USA

James E. Browning, and

Department of Cancer Epidemiology \& Genetics, H. Lee Moffitt Cancer Center \& Research Institute, Tampa, FL 33612, USA

\section{Y. Ann Chen}

Department of Cancer Epidemiology \& Genetics, H. Lee Moffitt Cancer Center \& Research Institute, Tampa, FL 33612, USA

Department of Biostatistics, H. Lee Moffitt Cancer Center \& Research Institute, Tampa, FL 33612, USA

\footnotetext{
(C) Springer Science+Business Media, LLC. 2011

Correspondence to: Kathleen M. Egan.

kathleen.egan@moffitt.org .

Electronic supplementary material The online version of this article (doi:10.1007/s11060-010-0506-0) contains supplementary material, which is available to authorized users.

Conflict of interest The authors have no conflicts of interest.
} 


\section{Abstract}

Malignant gliomas are the most common and deadly brain tumors. Although their etiology remains elusive, recent studies have narrowed the search for genetic loci that influence risk. We examined variants implicated in recent cancer genome-wide association studies (GWAS) for associations with glioma risk in a US case-control study. Cases were identified from neurosurgical and neuro-oncology clinics at major academic centers in the Southeastern US. Controls were identified from the community or were friends or other associates of cases. We examined a total of 191 susceptibility variants in genes identified in published cancer GWAS including glioma. A total of 639 glioma cases and 649 controls, all Caucasian, were included in analysis. Cases were enrolled a median of 1 month following diagnosis. Among glioma GWASidentified variants, we detected associations in CDKN2B, RTEL1, TERT and PHLDB1, whereas we did not find overall associations for $C C D C 26$. Results showed clear heterogeneity according to histologic subtypes of glioma, with TERT and RTEL variants a feature of astrocytic tumors and glioblastoma (GBM), CCDC26 and PHLDB1 variants a feature of astrocytic and oligodendroglial tumors, and $C D K N 2 B$ variants most prominent in GBM. No examined variant in other cancer GWAS was found to be related to risk after adjustment for multiple comparisons. These results suggest that GWAS-identified SNPs in glioma mark different molecular etiologies in glioma. Stratification by broad histological subgroups may shed light on molecular mechanisms and assist in the discovery of novel loci in future studies of genetic susceptibility variants in glioma.

\section{Keywords}

Genotype; Glioma; Susceptibility; Single nucleotide polymorphism

\section{Introduction}

Glioma is one of the least understood and most aggressive human tumors. Risk factors for glioma remain largely unknown. A role for heredity is suggested by the occurrence of familial clustering of the disease. Relatives of patients with glioma are at increased risk for these tumors. Moreover, there are well-recognized genetic syndromes associated with increased risk including the Turcot and Li-Fraumeni syndromes, neurofibromatosis type 1 and multiple enchondromatosis. Genetic susceptibility for glioma has also been suggested in numerous case-control studies [1]. The availability of commercial arrays that capture most common variation in the genome has made possible genome-wide association studies (GWAS) which have successfully identified several hundred common genetic variants associated with cancer [2], some linked to multiple cancer phenotypes. Two GWAS in glioma concordantly identified variants in CDKN2B, RTEL1 and TERT [3, 4] although results for other loci were not replicated in the two studies.

The GWAS of Wrensch et al. [3] involved genotyping 275,895 autosomal variants among 692 adult high-grade glioma (GBM and anaplastic astrocytoma) cases drawn mainly from the San Francisco Adult Glioma Study (AGS) and 3,992 controls. For replication, they analyzed 13 SNPs with $P<10^{-6}$, which included markers in the genes $C D K N 2 B, R T E L 1$ and $T E R T$, using independent data from 176 high-grade glioma cases and 174 controls from the Mayo Clinic. Validation analyses confirmed the presence of risk loci for glioma in the region of $C D K N 2 B$ and RTEL1.

The GWAS of Shete et al. [4] involved a meta-analysis of two genome-wide association studies among Caucasian adults enrolled from the Interphone Study [5] in the UK and from MD Anderson Cancer Center in the US totaling 1,878 cases and 3,670 controls. Validation was provided by 3 independent European case-control studies totaling 2,545 cases and 
2,953 controls. In a panel of 550K tagging SNPs, these investigators identified risk loci for glioma at TERT, CCDC26, CDKN2B, RTEL1 and PHLDB1, each with a combined $P$-value of $1.07 \times 10^{-8}$ or less. A total of 34 SNPs showed evidence of association at $P<10^{-5}$ in the discovery GWAS, including multiple loci not identified in the GWAS of Wrensch et al. [3].

While findings from the two GWAS point to a role for $C D K N 2 A-C D K 4$ pathway and telomere function in glioma occurrence, the importance of other identified loci remains unclear. Moreover, the impact of these variants across the spectrum of glioma, a heterogenous tumor encompassing glioblastoma (GBM), the most common and aggressive astrocytic tumor, anaplastic and lower grade astrocytomas, oligodendroglioma and mixed oligoastrocytomas, has not yet been examined. Finally, the possibility that variants identified in GWAS of other primary cancers might impact glioma risk has not been explored. To shed further light on genes conferring susceptibility to glioma, we examined the panel of SNPs implicated in recent cancer GWAS in a large series of cases and controls enrolled in the Southeastern Study of Glioma in Adults (GlioSE), a multicenter, clinic-based case-control study conducted at medical centers in the Southeastern US, a region with excess brain tumor-associated mortality [6].

\section{Subjects and methods}

\section{Study population}

The study population was comprised of participants in an ongoing, clinic-based case-control study in the United States. Cases were comprised of English-speaking persons aged 18 and older with a recent diagnosis of primary (nonrecurrent) glioma identified in neurosurgery and neuro-oncology clinics at several major medical and oncology centers in the Southeastern US including Vanderbilt University Medical Center in Nashville, Tennessee; Moffitt Cancer Center \& Research Institute in Tampa, Florida; the University of Alabama at Birmingham; Emory University in Atlanta, Georgia and the Kentuckiana Cancer Institute in Louisville, Kentucky.

Controls were comprised of friends, in-laws and other associates of the cases and persons sampled from the same communities as the cases identified from white page listings. Controls reporting a personal history of brain tumor were excluded from analysis.

Cases were enrolled a median of 1 month following the diagnosis of glioma (interquartile range: 2 weeks- 1.7 months). The majority of eligible glioma patients (87\%) participated in the study and provided a DNA sample. Of those not included in the study, $7 \%$ refused (generally due to illness) and 6\% died before they could be approached or a DNA sample could be collected after providing informed consent. Among community controls, $49.6 \%$ of confirmed eligible households yielded a study participant.

DNA samples were self-collected by oral rinse or the saliva method using Oragene kits (www.dnagenotek.com). Collected samples were sent by participants or study personnel to the Core Genotyping Facility at Vanderbilt (during the pilot phase) or to the Tissue Core at Moffitt for DNA extraction and storage.

The study was approved by Investigational Review Committees at each participating center and all subjects enrolled in the study provided written informed consent.

\section{SNP genotyping}

Genotyping was completed using Illumina's GoldenGate technology (Illumina, San Diego, CA) at the Center for Genome Technology at the Hussman Institute for Human Genomics, University of Miami. We developed a custom panel of 1536 SNPs that included 210 SNPs 
in genes linked to cancer in GWAS or large consortial studies (see Appendix 1). For glioma, the list included 34 SNPs reported in the GWAS of Shete et al. with a combined $P$-value of $<0.01$ in the discovery GWA and replication studies [4]. We also included 6 top nonredundant hits in the GWAS of Wrensch et al. [3]. Putatively functional SNPs among implicated genes were also included in the panel. In addition, we included 130 SNPs identified in GWAS of other cancers published up to Summer 2009

(http://www.genome.gov/gwastudies/). A list of genes, chromosomal location, and position for the SNPs included in the analysis is available online. Quality control samples (water, CEPH DNA, as well as blinded and unblinded DNA samples) were included in genotyping assays. Laboratory staff was blinded to the case-control status of the sample.

Genotyping with acceptable completion rates was accomplished for 191 of 210 (91\%) attempted SNPs. All but one of the 191 SNPs (RTEL1 rs7261546) satisfied the HardyWeinberg Equilibrium among controls at a nominal $P$-value of 0.01 . Concordance of genotype calls in 95 blinded duplicate pairs ranged from 94 to $100 \%$ (mean, 99.8\%) and the genotyping success rate ranged from 86 to $100 \%$ (mean, $95.0 \%$ ).

A total of 699 glioma cases and 704 controls were submitted for genotyping. We excluded 33 cases $(4.7 \%)$ and 31 controls $(4.4 \%)$ with low call rates ( $<75 \%)$, and a further 27 cases (3.9\%) and 24 controls (3.4\%) who reported 1 or 2 non-Caucasian parents, leaving 639 glioma cases and 649 controls (including 550 community and 99 'friend' controls) available for general analysis. Based on a review of diagnostic pathology reports, the case group was comprised of 354 (55\%) GBMs (ICD-O code [7] 9440/3); 153 (24\%) lower grade pure astrocytic tumors including 77 grade 3 anaplastic astrocytoma (ICD-O 9401/3) and 76 grade 1 or 2 astrocytomas (ICD-O 9384/1, 9421/1, 9400/3, 9424/3); 99 (16\%) mixed oligodendroglial and astrocytic tumors (ICD-O 9382/3) or pure oligodendrogliomas (ICD-O $9450 / 3,9451 / 3)$, and 33 rare glioma variants $(N=16)$ or glioma with unspecified histology $(N=13)$ or unspecified histology and grade, e.g. 'glioma, NOS' $(N=4)$. As eligibility in the case-control study required a recent (within 3 months) diagnosis of glioma, only primary GBM and de novo anaplastic astrocytoma (e.g. nonrecurrences) were represented in the case group for these diagnoses.

A total of 349 of 354 patients with GBM had known vital status a minimum of 3 months after the diagnosis of glioma. Among them, 221 died from the tumor a median of 10.9 months (range: $0.8-57.9$ months) following diagnosis. The median duration of follow up among 128 surviving patients was 10.9 months (range: $3.1-44.6$ months).

\section{Statistical analysis}

Unconditional multivariate logistic regression adjusting for age and gender was used to estimate odds ratios and 95\% confidence intervals for individual SNPs assuming an additive model. A score test of linear trend was conducted for each SNP using a three-level ordinal variable corresponding to the number of minor alleles for the SNP $(0,1$ or 2$)$. Multinomial logistic regression was used to evaluate genotype associations according to glioma subtypes including GBM, other astrocytic tumors, and a combination of oligodendroglial and mixed oligoastroglial tumors in the 16 'top-hit' (e.g. those with smallest $P$-values) SNPs reported in published glioma GWAS. Cox proportional hazards regression was used to assess whether genotypes were associated with mortality rates among the GBM cases. All regression analyses were performed using SAS (SAS Institute, Inc., Cary). To control the rate of type 1 error in multiple tests for association among loci identified for other cancers, we adjusted $P$-values using the method of Benjamini and Hochberg [8]. 


\section{Results}

The median age at enrollment was 55 years (range: 19-89) in cases and 58 years (range: 1989 ) in controls. Males comprised $62 \%$ of cases and $57 \%$ of controls. The majority of subjects resided in Tennessee (30\%) or Florida (25\%), whereas a smaller number resided in Alabama (14\%), Kentucky (14\%), Georgia (11\%), or another state $(6 \%)$.

Table 1 shows results for genes representing top hits in glioma GWAS for TERT, CCDC26, $C D K N 2 B, P H L D B 1$ and RTEL1. With the exception of SNPs in CCDC26, we observed significant associations in all of the implicated SNPs. For RTEL1, in addition to the GWASidentified SNPs, we examined 3 coding region SNPs (not shown). A nonsynonymous SNP (N124S; rs3848668) located upstream of the GWAS variants was not significantly associated with glioma risk $\left(P_{\text {trend }}=0.252\right)$. In contrast, one synonymous $(\mathrm{D} 664 \mathrm{D}$; rs6062302) and one nonsynonymous (Q1042H; rs3208008) SNP, in tight linkage disequilibrium with 2 of the GWAS SNPs (rs6010620 and rs2297440) had strong associations with glioma risk $\left(P_{\text {trend }}<0.001\right)$.

We examined 'top-hit' glioma GWAS SNPs according to grade and histological subtype of glioma (Table 2). TERT rs 2736100 was significantly associated only with high-grade tumors $(\mathrm{GBM})\left(\mathrm{P}_{\text {trend }}<0.001\right)$ whereas weaker and nonsignificant associations were observed for lower grade pure astrocytic and oligodendroglial tumors (a combination of pure oligodendroglial and mixed astrocytic). A similar pattern was observed for the $C D K N 2 B$ SNPs. The results for $C C D C 26$, null in the combined analyses, suggested a significant association for oligodendroglial tumors and a borderline association for lower grade pure astrocytic tumors. PHLDBI rs498872 was significant only in lower grade astrocytic tumors $\left(P_{\text {trend }}=0.001\right)$ with a borderline association also observed among the oligodendrogliomas $\left(P_{\text {trend }}=0.042\right)$. For the RTEL1 SNPs, associations were confined to the astrocytic tumors whereas these SNPs had no association with oligodendroglial tumors.

A case-only analysis (Table 3) showed a deficit of variant alleles in RTEL1 rs4809324 (OR: $0.50 ; 95 \%$ CI $\left.0.28-0.91 ; P_{\text {trend }}=0.023\right)$ in oligodendroglial tumors when compared to GBM; the same pattern was observed for all $4 C D K N 2 B$ SNPs. In contrast, an excess of variant alleles was observed in CCDC26 rs4809324, rs16904140 and rs4295627 for oligodendroglial and astrocytic tumors when compared to GBM. Deleterious alleles in PHLDB1 rs 498872 were approximately $40 \%$ more common for astrocytic tumors than GBM $\left(\mathrm{OR}: 1.41 ; 95 \%\right.$ CI $\left.1.04-1.92 ; P_{\text {trend }}=0.028\right)$. Genotype frequencies were not significantly different comparing astrocytic and oligodendroglial tumors.

In the GWAS of Shete et al. of 34 SNPs with a high level of significance $\left(P<10^{-5}\right)$ in the GWA studies, 20 did not achieve an accepted threshold for genome-wide significance $(P<5$ $\times 10^{-7}$ ) after pooling with the replication studies. We examined all of these SNPs (not shown) and observed nominally significant associations in 2 of them. The latter included an intergenic SNP (rs7300686) on chromosome 12 (overall $\left.P_{\text {trend }}=0.012\right)$ in which the association was significant only among astrocytic tumors (per allele OR: $1.39 ; P_{\text {trend }}=$ $0.012)$ and an intergenic SNP (rs1384847) on chromosome 4 (overall $\left.P_{\text {trend }}=0.043\right)$ in which the association was driven mainly by association with GBMs (per allele OR: 1.46; $P_{\text {trend }}=0.028$ ). All of the remaining 18 variants were null in the present data (not shown).

We included in our panel 3 SNPs identified uniquely in the GWAS of Wrensch et al. [3] which included primarily GBMs: CSF1R rs 10079250 on chromosome 5, rs11163687 on chromosome 7 near the gene TTLL7 and rs11823971 on chromosome 11 near the gene PDE2A. There was no evidence of LD between the SNP on chromosome 5 and the TERT SNPs $\left(R^{2}=0.008, D^{\prime}=0.37\right.$ for rs2736100 in TERT in HapMap) or the SNP on chromosome 11 and the PHLDB1 SNP $\left(R^{2}=0.008\right.$ and $D^{\prime}=0.20$ in HapMap). We did not 
find evidence of association for these 3 SNPs with glioma risk, overall, or for GBM only, although all 3 variants were uncommon (MAF: 5, 13 and 9\% in controls, respectively), limiting our power. However, we did observe borderline associations within astrocytic tumors for rs 11163687 (OR: $0.58 ; 95 \%$ CI $\left.0.36-0.93 ; P_{\text {trend }}=0.024\right)$ and $\operatorname{rs} 10079250(\mathrm{OR}$ : 1.88 ; 95\% CI: $\left.1.09-3.25 ; P_{\text {trend }}=0.023\right)$.

Finally, we examined associations of 'top-hit' glioma GWAS SNPs with survival among the GBM cases. None of the GWAS-identified SNPs in Table 1 were found to be related to patient survival times with statistical significance.

Among 116 examined SNPs identified in GWAS of other primary cancers (Supplemental data), none were significantly associated with glioma risk after adjustment for multiple testing.

\section{Discussion}

The current study provides evidence that susceptibility variants identified in published glioma GWAS differ among GBM, lower grade astrocytic tumors and oligodendrogliomas and mixed tumors. While these categories are broad, they define tumors with different clinical behavior and/or arising from cells with distinct functions in the CNS [9] making distinguishing patterns in the genomic background plausible. Results have implications for interpreting published GWAS and for planning future GWAS which these data suggest should consider potential heterogeneity according to recognized histopathological subtypes of glioma.

In the present study, variants in $C C D C 26$ and $P H L D B 1$ were associated primarily with astrocytic and oligodendroglial tumors. CCDC26 rs4295627 provided the strongest signal in the Shete GWAS [4]. Consistent with the GWAS of Wrensch et al. [3] we did not detect association for $C C D C 26$ rs 4295627 or 4 other variants in $C C D C 26$ also linked to risk in the Shete GWAS in a combined analysis. However, we were able to detect strong associations among astrocytic tumors and tumors with an oligodendroglial component. This finding helps reconcile results of the 2 GWAS as the study by Wrensch et al. was limited to high-grade astrocytic tumors (84\% GBM and 16\% anaplastic astrocytomas). The SNP rs498872 which maps to the 5'UTR of PHLDB1 provided the fifth-strongest signal in the Shete GWAS [4]. This variant was also not detected by Wrensch et al. and in the current study, an association was limited to lower grade astrocytomas and oligodendrogliomas. Taken together, the findings suggest that both $C C D C 26$ and $P H L D B 1$ play a limited role in the genesis of primary GBM.

In these data, variants in TERT, RTEL and $C D K N 2 B$ were primarily a feature of astrocytic tumors and GBM. TERT rs2736100, CDKN2B rs4977756 and RTEL1 rs6010620 provided the second, third and fourth strongest signal, respectively, in the GWAS of Shete et al. [4] and were concordantly identified in the GWAS of Wrensch et al. [3] (although the TERT SNP was detected only in the discovery (AGS) data in the latter GWAS). In the current study, TERT rs 2736100 was significantly associated only with GBM whereas RTEL1 rs6010620 was more strongly associated with the lower grade astrocytic tumors. Variants in $C D K N 2 B$ were most prominent in GBM although odds ratios were nonsignificantly elevated also for astrocytic tumors. The suggestion from these data that genetic variation in TERT, $R T E L$ and $C D K N 2 B$ play a more prominent role in tumors with astrocyte lineage should be explored in larger studies.

We examined association of the variants in these genes (listed in Table 1) with mortality rates in our series of GBM patients and could demonstrate no significant associations. A recent study [10] suggested that CCDC26 rs10464870 and rs891835 and RTEL1 rs2297440 
and rs6010620 predict long-term survival ( $\geq 36$ months) in GBM. We failed to detect overall association of these variants with GBM mortality. Too few deaths occurred more than 36 months after diagnosis (a total of 5 deaths among 9 patients which survived that duration) for a meaningful analysis according to survival time.

In addition to top-hit variants in these 5 genes, we detected associations in 2 intergenic SNPs identified the Shete GWAS (rs1384847 and rs7300686) [4]. Both of these SNPs were significant in the discovery GWA but not the replication studies. Neither variant was in linkage dis-equilibrium with any implicated SNP on chromosomes 4 and 12, respectively, in the Wrensch GWAS (not shown) [3]. Furthermore, there was no evidence in our data that associations involving these variants were confined to lower grade astrocytic tumors and/or oligodendrogliomas. Three variants identified uniquely in the Wrensch GWAS [3] were not associated with risk in current study, overall, or among high-grade tumors. Further research is needed to establish the relevance of these SNPs in gliomagenesis.

We examined SNPs identified in GWAS of other cancers published up to Summer 2009 and found modest associations in several variants, although none remained significant after adjustment for multiple comparisons. An exception is TERT rs 2736100 which was identified in both glioma GWAS and has also been implicated in GWAS of testicular germ cell tumors [11] and lung cancer [12-14]. An intronic SNP (rs402710) located in CLPTMIL near TERT, identified in lung cancer GWAS [14], was marginally associated with risk in the current data $\left(P_{\text {trend }}=0.039\right)$ before adjustment; this SNP is uncorrelated with TERT rs2736100 and TERT rs 2853676 (not shown). The CLPTMIL SNP was marginally associated with GBM mortality in the current data (HR: $1.40 ; 95 \%$ CI $\left.1.07-1.84 ; P_{\text {trend }}=0.015\right)$ whereas the TERT SNPs had no association with mortality. The SNP rs6983267 near POU5F1P1 on chromosome 8 is multicancer susceptibility marker linked to prostate [15], colon [16], and a range of other cancers [17]. This variant showed no association with glioma in the present series. Two breast cancer variants in FGFR2 (rs1219648 and rs2981582) [18] were each marginally associated with glioma risk before adjustment; that amplification of FGFR2 has been noted in GBM [19] suggests these variants may have a causal role in glioma and should be examined in larger studies.

Strengths of the current study include the relatively large sample size for a study of a rare tumor such as glioma, pathologic confirmation of all cases, and the limited potential influence of survival bias given exceptionally rapid enrollment of cases. However, the study had several limitations. Our study had limited power to detect associations with rare variants and those with modest relative risks, and the study size only permitted us to examine associations according to broad histological strata of glioma. Our classification of tumors by histology was based on the diagnostic pathology reports and some misclassification was possible [20]. We note, however, that our results are consistent with those in a recent report that showed distinct patterns of association for the five most prominent SNPs in the Shete GWAS according to WHO grade of glioma [21]. As in the current study, risk alleles for TERT rs2736100 were strongly correlated with the diagnosis of GBM whereas carrier frequencies of risk alleles of CCDC26 rs 4295627 and $P H L D B 1$ rs 498872 were inversely correlated with GBM histology (RTEL1 rs6010620 had a stronger association with GBM in that study). In both series, $C D K N 2 B$ rs 4977756 risk allele frequency did not vary strongly by histology in astrocyte lineage tumors. Concordance of results in the two studies suggests that classification in the current study was reasonably accurate at least among the astrocytic tumors. Finally, we could not evaluate effects of genotypes by race as $\sim 98 \%$ of subjects enrolled in the study were Caucasian. Racial admixture among Caucasians in the study was not evaluated (approximately 93\% of cases and $95 \%$ of controls reported European ancestry in one or both parents) and may have diluted some associations. 
Rapid advances have recently been made in understanding genes and signaling networks involved in the incidence and pathogenesis of glioma [22]. The current results suggest that stratification by broad histological subgroups has the potential to uncover novel risk loci and may shed additional light on genetic susceptibility to glioma in future studies.

\title{
Supplementary Material
}

Refer to Web version on PubMed Central for supplementary material.

\section{Acknowledgments}

\begin{abstract}
The authors wish to acknowledge study participants for their contributions. We further wish to thank the clinicians and research staffs at participating medical centers. Special thanks go to Celia Sigua and Marek Wloch of the Tissue Core at Moffitt and Cara Sutcliffe of the Center for Human Genetics Research DNA Resources Core at Vanderbilt University School of Medicine for their work in processing DNA samples, and Ms. Anna Konidari and staff at the Center for Genome Technology at the Hussman Institute for Human Genomics, University of Miami for their expert technical assistance in the genotyping phase of the study. This study was supported by a grant from the National Institutes of Health (CA R01CA116174) as well as institutional funding from the Moffitt Cancer Center, Tampa, FL and the Vanderbilt-Ingram Comprehensive Cancer Center, Nashville, TN.
\end{abstract}

\section{References}

1. Gu J, Liu Y, Kyritsis AP, Bondy ML. Molecular epidemiology of primary brain tumors. Neurotherapeutics. 2009; 6(3):427-435. [PubMed: 19560733]

2. Hindorff LA, Sethupathy P, Junkins HA, Ramos EM, Mehta JP, Collins FS, Manolio TA. Potential etiologic and functional implications of genome-wide association loci for human diseases and traits. Proc Natl Acad Sci USA. 2009; 106(23):9362-9367. [PubMed: 19474294]

3. Wrensch M, Jenkins RB, Chang JS, Yeh RF, Xiao Y, Decker PA, Ballman KV, Berger M, Buckner JC, Chang S, Giannini C, Halder C, Kollmeyer TM, Kosel ML, LaChance DH, McCoy L, O'Neill BP, Patoka J, Pico AR, Prados M, Quesenberry C, Rice T, Rynearson AL, Smirnov I, Tihan T, Wiemels J, Yang P, Wiencke JK. Variants in the CDKN2B and RTEL1 regions are associated with high-grade glioma susceptibility. Nat Genet. 2009; 41(8):905-908. [PubMed: 19578366]

4. Shete S, Hosking FJ, Robertson LB, Dobbins SE, Sanson M, Malmer B, Simon M, Marie Y, Boisselier B, Delattre JY, Delattre JY, Hoang-Xuan K, El Hallani S, Idbaih A, Zelenika D, Andersson U, Henriksson R, Bergenheim AT, Feychting M, Lönn S, Ahlbom A, Schramm J, Linnebank M, Hemminki K, Kumar R, Hepworth SJ, Price A, Armstrong G, Liu Y, Gu X, Yu R, Lau C, Schoemaker M, Muir K, Swerdlow A, Lathrop M, Bondy M, Houlston RS. Genome-wide association study identifies five susceptibility loci for glioma. Nat Genet. 2009; 41(8):899-904. [PubMed: 19578367]

5. Cardis E, Richardson L, Deltour I, Armstrong B, Feychting M, Johansen C, Kilkenny M, McKinney P, Modan B, Sadetzki S, Schüz J, Swerdlow A, Vrijheid M, Auvinen A, Berg G, Blettner M, Bowman J, Brown J, Chetrit A, Christensen HC, Cook A, Hepworth S, Giles G, Hours M, Iavarone I, Jarus-Hakak A, Klaeboe L, Krewski D, Lagorio S, Lönn S, Mann S, McBride M, Muir K, Nadon L, Parent ME, Pearce N, Salminen T, Schoemaker M, Schlehofer B, Siemiatycki J, Taki M, Takebayashi T, Tynes T, van Tongeren M, Vecchia P, Wiart J, Woodward A, Yamaguchi N. The INTERPHONE study: design, epidemiological methods, and description of the study population. Eur J Epidemiol. 2007; 22(9):647-664. [PubMed: 17636416]

6. Fang Z, Kulldorff M, Gregorio DI. Brain cancer mortality in the United States, 1986-1995: a geographic analysis. Neuro Oncol. 2004; 6:179-187. [PubMed: 15279710]

7. Louis, DN.; Ohgaki, H.; Wiestler, OD.; Cavenee, WK., editors. WHO classification of tumours of the central nervous system. IARC; Lyon: 2007.

8. Benjamini Y, Hochberg Y. Controlling the false discovery rate: a practical and powerful approach to multiple testing. J R Stat Soc. 1995; 57:289-300.

9. Verkhratsky, A.; Butt, A. Glial neurobiology. Wiley; Chichester, UK: 2007.

10. Liu Y, Shete S, Etzel CJ, Scheurer M, Alexiou G, Armstrong G, Tsavachidis S, Liang FW, Gilbert M, Aldape K, Armstrong T, Houlston R, Hosking F, Robertson L, Xiao Y, Wiencke J, Wrensch 
M, Andersson U, Melin BS, Bondy M. Polymorphisms of LIG4, BTBD2, HMGA2, and RTEL1 genes involved in the double-strand break repair pathway predict GBM survival. J Clin Oncol. 2010; 28(14):2467-2474. [PubMed: 20368557]

11. Turnbull C, Rapley EA, Seal S, Pernet D, Renwick A, Hughes D, Ricketts M, Linger R, Nsengimana J, Deloukas P, Huddart RA, Bishop DT, Easton DF, Stratton MR, Rahman N. UK testicular cancer collaboration. variants near DMRT1, TERT and ATF7IP are associated with testicular germ cell cancer. Nat Genet. 2010; 42(7):604-607. [PubMed: 20543847]

12. Landi MT, Chatterjee N, Yu K, Goldin LR, Goldstein AM, Rotunno M, Mirabello L, Jacobs K, Wheeler W, Yeager M, Bergen AW, Li Q, Consonni D, Pesatori AC, Wacholder S, Thun M, Diver R, Oken M, Virtamo J, Albanes D, Wang Z, Burdette L, Doheny KF, Pugh EW, Laurie C, Brennan P, Hung R, Gaborieau V, McKay JD, Lathrop M, McLaughlin J, Wang Y, Tsao MS, Spitz MR, Wang Y, Krokan H, Vatten L, Skorpen F, Arnesen E, Benhamou S, Bouchard C, Metsapalu A, Vooder T, Nelis M, Välk K, Field JK, Chen C, Goodman G, Sulem P, Thorleifsson G, Rafnar T, Eisen T, Sauter W, Rosenberger A, Bickeböller H, Risch A, Chang-Claude J, Wichmann HE, Stefansson K, Houlston R, Amos CI, Fraumeni JF Jr, Savage SA, Bertazzi PA, Tucker MA, Chanock S, Caporaso NE. A genome-wide association study of lung cancer identifies a region of chromosome $5 \mathrm{p} 15$ associated with risk for adenocarcinoma. Am J Hum Genet. 2009; 85(5):679-691. [PubMed: 19836008]

13. Wang Y, Broderick P, Matakidou A, Eisen T, Houlston RS. Role of 5p15.33 (TERT CLPTM1L), 6p21.33 and 15q25.1 (CHRNA5-CHRNA3) variation and lung cancer risk in never-smokers. Carcinogenesis. 2010; 31(2):234-238. [PubMed: 19955392]

14. McKay JD, Hung RJ, Gaborieau V, Boffetta P, Chabrier A, Byrnes G, Zaridze D, Mukeria A, Szeszenia-Dabrowska N, Lissowska J, Rudnai P, Fabianova E, Mates D, Bencko V, Foretova L, Janout V, McLaughlin J, Shepherd F, Montpetit A, Narod S, Krokan HE, Skorpen F, Elvestad MB, Vatten L, Njølstad I, Axelsson T, Chen C, Goodman G, Barnett M, Loomis MM, Lubiñski J, Matyjasik J, Lener M, Oszutowska D, Field J, Liloglou T, Xinarianos G, Cassidy A, Study EPIC. Vineis P, Clavel-Chapelon F, Palli D, Tumino R, Krogh V, Panico S, González CA, Ramón Quirós J, Martínez C, Navarro C, Ardanaz E, Larrañaga N, Kham KT, Key T, Bueno-de-Mesquita HB, Peeters PH, Trichopoulou A, Linseisen J, Boeing H, Hallmans G, Overvad K, Tjønneland A, Kumle M, Riboli E, Zelenika D, Boland A, Delepine M, Foglio M, Lechner D, Matsuda F, Blanche H, Gut I, Heath S, Lathrop M, Brennan P. Lung cancer susceptibility locus at 5p15.33. Nat Genet. 2008; 40(12):1404-1406. [PubMed: 18978790]

15. Liu H, Wang B, Han C. Meta-analysis of genome-wide and replication association studies on prostate cancer. Prostate. 2010 in press.

16. Tuupanen S, Turunen M, Lehtonen R, Hallikas O, Vanharanta S, Kivioja T, Björklund M, Wei G, Yan J, Niittymäki I, Mecklin JP, Järvinen H, Ristimäki A, Di-Bernardo M, East P, CarvajalCarmona L, Houlston RS, Tomlinson I, Palin K, Ukkonen E, Karhu A, Taipale J, Aaltonen LA. The common colorectal cancer predisposition SNP rs6983267 at chromosome 8q24 confers potential to enhanced Wnt signaling. Nat Genet. 2009; 41(8):885-890. [PubMed: 19561604]

17. Wokolorczyk D, Gliniewicz B, Sikorski A, Zlowocka E, Masojc B, Debniak T, Matyjasik J, Mierzejewski M, Medrek K, Oszutowska D, Suchy J, Gronwald J, Teodorczyk U, Huzarski T, Byrski T, Jakubowska A, Górski B, van de Wetering T, Walczak S, Narod SA, Lubinski J, Cybulski C. A range of cancers is associated with the rs6983267 marker on chromosome 8. Cancer Res. 2008; 68(23):9982-9986. [PubMed: 19047180]

18. Hunter DJ, Kraft P, Jacobs KB, Cox DG, Yeager M, Hankinson SE, Wacholder S, Wang Z, Welch R, Hutchinson A, Wang J, Yu K, Chatterjee N, Orr N, Willett WC, Colditz GA, Ziegler RG, Berg CD, Buys SS, McCarty CA, Feigelson HS, Calle EE, Thun MJ, Hayes RB, Tucker M, Gerhard DS, Fraumeni JF Jr, Hoover RN, Thomas G, Chanock SJ. A genome-wide association study identifies alleles in FGFR2 associated with risk of sporadic postmenopausal breast cancer. Nat Genet. 2007; 39(7):870-874. [PubMed: 17529973]

19. Cancer Genome Atlas Research Network. Comprehensive genomic characterization defines human GBM genes and core pathways. Nature. 2008; 455(7216):1061-1068. [PubMed: 18772890]

20. Trembath D, Miller CR, Perry A. Gray zones in brain tumor classification: evolving concepts. Adv Anat Pathol. 2008; 15(5):287-297. [PubMed: 18724102] 
21. Simon M, Hosking FJ, Marie Y, Gousias K, Boisselier B, Carpentier C, Schramm J, Mokhtari K, Hoang-Xuan K, Idbaih A, Delattre JY, Lathrop M, Robertson LB, Houlston RS, Sanson M.

Genetic risk profiles identify different molecular etiologies for glioma. Clin Cancer Res. 2010; 16(21):5252-5259. [PubMed: 20847058]

22. Huse JT, Holland EC. Targeting brain cancer: advances in the molecular pathology of malignant glioma and medulloblastoma. Nat Rev Cancer. 2010; 10(5):319-331. [PubMed: 20414201] 


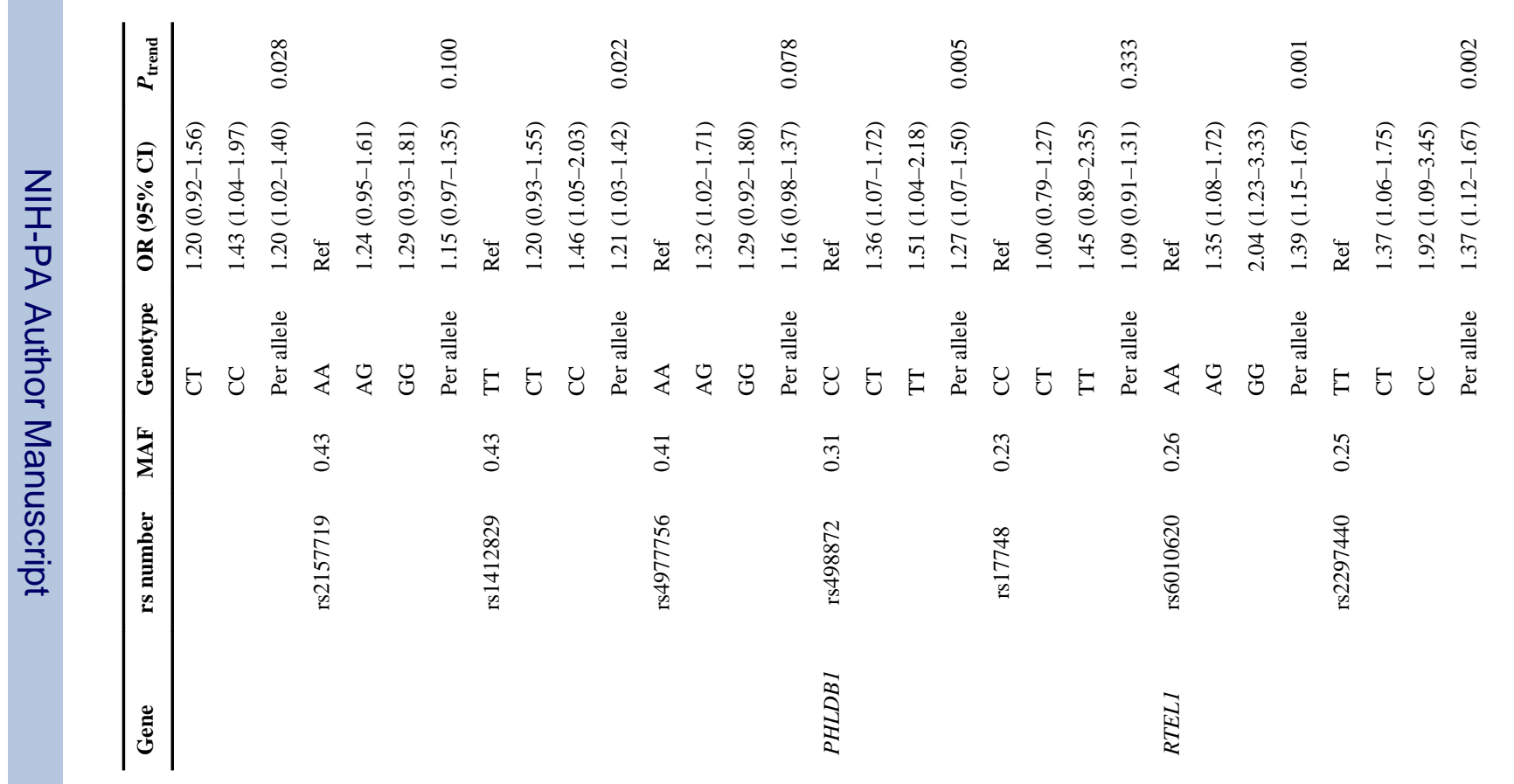




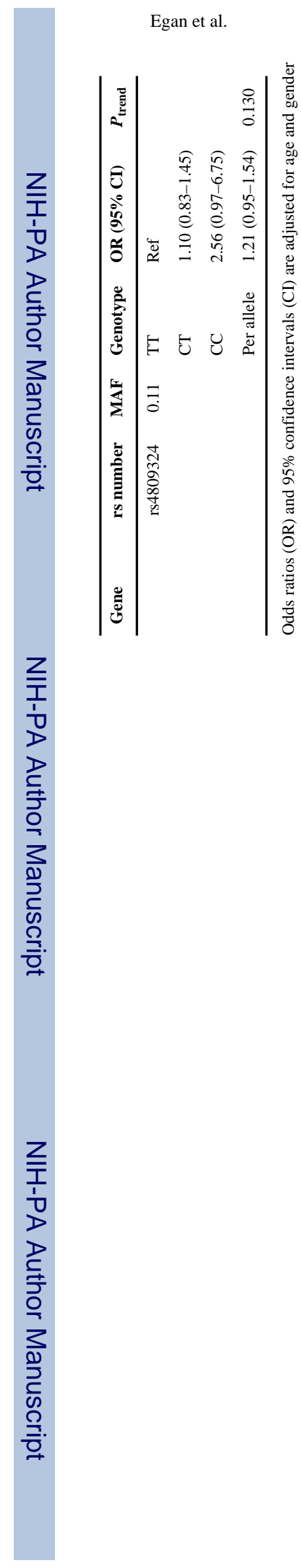

J Neurooncol. Author manuscript; available in PMC 2011 September 1. 


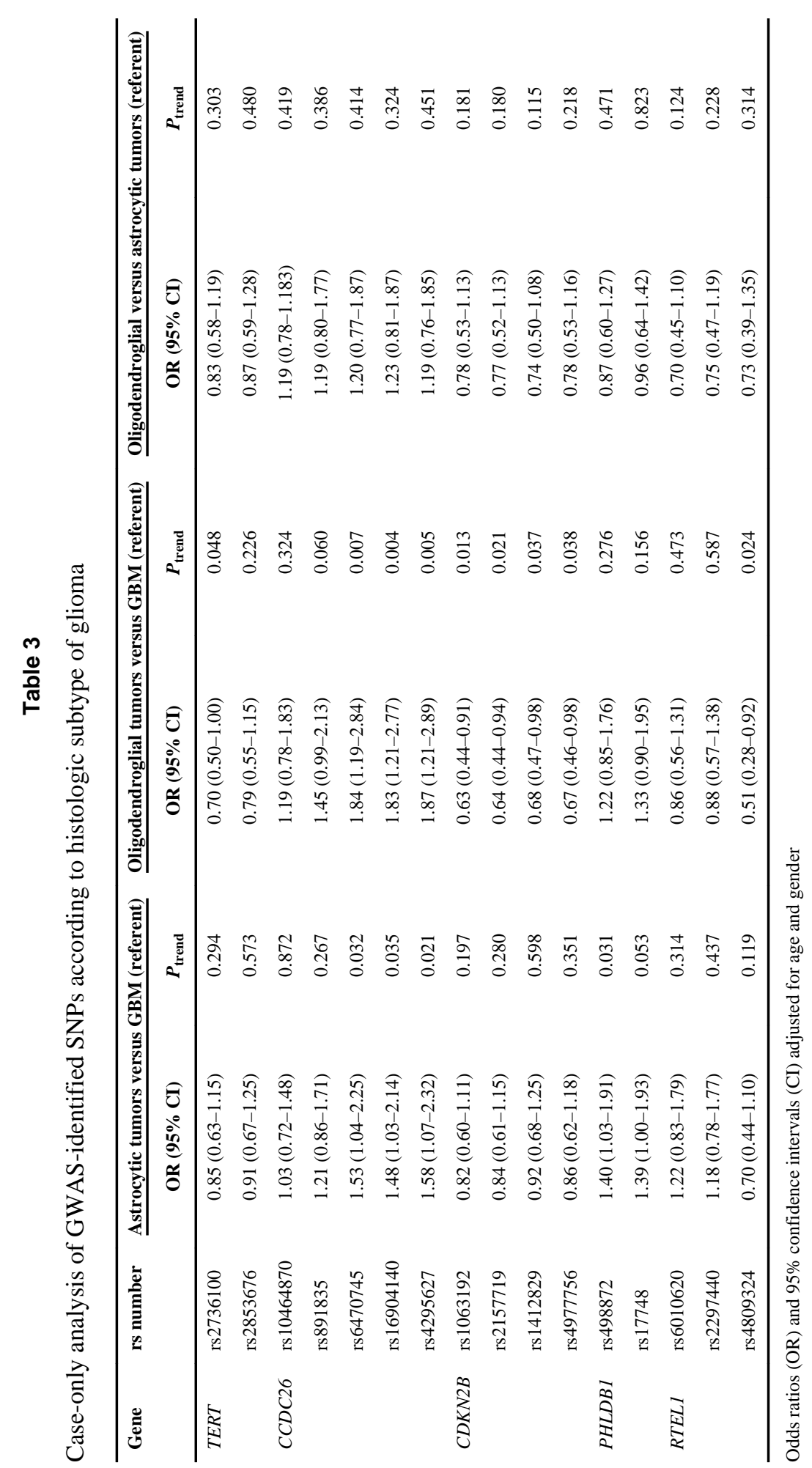

